\title{
Hospitalized patients with heart failure: the impact of anxiety, fatigue, and therapy adherence on quality of life
}

Maria Polikandrioti ${ }^{1,2}$, loannis Koutelekos ${ }^{2}$, George Panoutsopoulos ${ }^{3}$, Georgia Gerogianni², Afroditi Zartaloudi², Evangelos Dousis², Fotoula Babatsikou², Georgia Toulia²

${ }^{1}$ Technological Institution, Athens, Greece

${ }^{2}$ Nursing Department, University of West Attica, Athens, Greece

${ }^{3}$ Department of Nursing, Faculty of Human Movement and Quality of Life Sciences, University of Peloponnese, Sparta, Lakonia, Greece

Submitted: 18 August 2019

Accepted: 12 October 2019

Arch Med Sci Atheroscler Dis 2019; 4: e268-e279

DOI: https://doi.org/10.5114/amsad.2019.90257

Copyright (c) 2019 Termedia \& Banach

\section{Abstract}

Introduction: Heart failure (HF) is a major global health problem associated with increased morbidity and mortality and reduced quality of life $(\mathrm{QoL})$. The aim of the study was to assess the impact of anxiety, fatigue and adherence to therapeutic guidelines on HF patients' QoL.

Material and methods: A hundred and twenty hospitalized HF patients were enrolled in the study. Data collection was performed by completion of the Minnesota Living With Heart Failure Questionnaire (MLHFQ), the Greek version of the Modified Fatigue Impact Scale (MFIS-Greek), the Zung Self-Rating Anxiety Scale (SAS) and a questionnaire that measured adherence to therapeutic guidelines.

Results: Data analysis showed moderate levels of anxiety and high levels of adherence to therapeutic guidelines as well as moderate to large effects of HF on patients' fatigue and QoL. A statistically significant positive linear association was observed between anxiety and QoL (rho >0.6) as well as fatigue and QoL (rho > 0.3). An increase in the anxiety or fatigue score indicated an increase also in the QoL score, meaning that the more anxiety and fatigue a patient felt the worse the QoL also was. Moreover, a statistically significant negative linear association was observed between adherence to therapeutic guidelines and QoL (rho < -0.2). An increase in adherence score indicated a decrease in QoL score, meaning that the more adherent a patient was the better was the QoL.

Conclusions: The present findings suggest that QoL may be improved when adherence to therapy is increased and fatigue and anxiety are alleviated.

Key words: heart failure, anxiety, fatigue, treatment adherence, quality of life.

\section{Introduction}

During recent decades, heart failure (HF) has been increasing at an alarming rate, affecting more than 26 million individuals worldwide [1], 5.7 million Americans [2, 3] and 15 million Europeans [4]. According to estimates, more than 8 million individuals will be affected by 2030, representing a $46 \%$ increase in prevalence [5]. Interestingly, HF is predominantly a disease of the elderly, as prevalence doubles in each decade of life $[1,5,6]$. HF implies a substantial burden not only for patients and but

\author{
Corresponding author: \\ Prof. Maria Polikandrioti \\ Nursing Department \\ University of West Attica \\ Ag. Spyridon 28 Aigaleo \\ Athens 122 42, Greece \\ Phone: +3316972425054 \\ E-mail: mpolik2006@yahoo. \\ com
}


also for healthcare systems in developed countries [7]. HF is the most common reason for hospital admission in patients above 65 years old [8]. For instance, in the USA the number of HF hospitalizations tripled from 1.27 to 3.86 million between 1979 and $2004[9,10]$.

Furthermore, HF accounts for frequent re-hospitalizations [2]. Interestingly, re-admissions approach $30 \%$ within 60 to 90 days $[11,12], 25 \%$ within 30 days [13] and $50 \%$ after 6 months of initial hospitalization [2]. Moreover, HF accounts for $1-3 \%$ of total health care expenditures [1], of which two thirds are attributed to hospitalization [4]. Finally, this life-threatening disease is associated with increased mortality as $50-75 \%$ of patients die within 5 years after diagnosis $[14,15]$.

In spite of recent advances in diagnosis and in the therapeutic regimen including new medicines, hemodynamic monitoring and device therapies, $\mathrm{HF}$ prevalence still remains high [2]. It is noteworthy that HF related issues such as prevalence, morbidity and mortality vary globally and discrepancies may be attributed to the instruments used, to sample studied (small, unrepresentative and cross sectional designs), to socio-economic status and other disparities $[1,16]$.

$\mathrm{HF}$ is a complex clinical syndrome resulting from impairment of ventricular filling or ejection of blood accompanied by dyspnea, fatigue, peripheral or pulmonary edema [17].

Efficacy of treatment is evaluated by parameters such as laboratory findings which represent quantifiable outcomes. These indices ignore patients' needs or difficulties in daily life that adversely affect quality of life (QoL) [18-20]. According to patients' view, the main determinants of QoL include current health state, social integration, spirituality, perceived support, self care behaviors, sleep disorders and emotional burden [16, 19, 20].

Nowadays, HF treatment aims not only at reducing mortality but also at attaining an acceptable level of QoL which permits patients to pursue happiness or enjoy spending time with significant others. Measuring QoL is obviously one of the most effective ways to explore patients' clinical status according to their perceptions, to screen deteriorations in daily functioning and ultimately to improve patterns of care $[16,18,19]$. Hospitalization is the most proper time to plan effective clinical approaches tailored to patients' needs [11, 20].

To the best of our knowledge, little is known about determinants of QoL in the hospitalized HF population in Greece. Additionally, there no available studies that determine the importance of measurements of anxiety, fatigue, and treatment adherence with respect to QoL.

Thus, this cross-sectional study was carried out to determine the impact of anxiety, fatigue and ad- herence to therapeutic guidelines on QoL of hospitalized HF patients and explore the associated demographic, clinical, and self-reported characteristics.

\section{Material and methods}

\section{Study population}

The sample of the study consisted of 120 hospitalized HF patients. Convenience sampling was used. The study included patients admitted to public hospitals during the period February 2018November 2018.

Criteria for including a patient in the study were: a) good comprehension of Greek language, b) HF diagnosis confirmed by medical record, c) not receiving anti-anxiety or antidepressant medications, d) no other chronic disease that might affect QoL (e.g., cancer, chronic kidney disease) and e) no alcohol consumption within the last three years. The exclusion criteria were absence of psychiatric or cognitive problems. One hundred and forty-two participants were screened according to the inclusion and exclusion criteria. Among them, 10 did not meet the entry criteria and 12 did not agree to participate. All of them (22 participants) were excluded from the sample. Therefore, the final sample consisted of 120 participants.

Hospitalized patients who met the inclusion criteria were approached by the researcher and were explained about the nature and the objectives of the study. Also, they were assured of the confidentiality of the information. All participants gave their written informed consent to take part in an interview.

In the present study there was no intervention or control group since this research merely recorded whether patients experienced anxiety, fatigue, whether they were adherent to therapeutic guidelines and their impact on QoL.

The process of filling out the questionnaires lasted between 15 and 30 min and took place for all participants: a) the second day of hospital admission since the questionnaires used evaluate how respondents felt during the previous week and b) at evening shifts when patients had no tasks to perform such as laboratory or other tests.

\section{Ethical considerations}

The study was approved by the Medical Research Ethics Committee of the hospital that took part in this study and it was conducted in accordance with the Declaration of Helsinki (1989) of the World Medical Association.

\section{Data variables}

Data collection was performed by the method of the interview using: a) the Minnesota Liv- 
ing With Heart Failure Questionnaire (MLHFQ) to measure QoL, b) the Greek version of the Modified Fatigue Impact Scale (MFIS-Greek) to measure fatigue, c) the Self-rating Anxiety Scale (SAS) - Zung to measure anxiety and d) a questionnaire that measured patients' adherence to therapeutic guidelines. Data collected for each patient also included demographic, clinical and other self-reported characteristics.

\section{Measuring QoL of hospitalized HF patients}

To evaluate QoL, the Minnesota Living With Heart Failure Questionnaire (MLHFQ) was used [21]. The scale consists of 21 questions that assess patients' QoL in the last month (4 weeks). Respondents are able to answer every question in a Likert type scale (scores from 0 to 5). Two separate groups of questions are: a) the physical state and $b$ ) the mental state. The score assigned to the questions is summed separately to questions that assess physical state, for those that assess mental state and all questions together to an aggregate score, the total QoL. Higher values of scores indicate poorer QoL.

\section{Measuring fatigue of hospitalized $\mathrm{HF}$ patients}

To evaluate fatigue, the Greek version of the Modified Fatigue Impact Scale (MFIS-Greek) was used. This scale was translated into Greek by Bakalidou et al. [22], with good reliability and validity. The scale consists of 21 questions that assess fatigue of patients in the last month (4 weeks). Respondents are able to answer every question in a Likert type scale (scores from 1 to 5 ). Two separate groups of questions are distinguished: a) the physical fatigue of patients and b) the mental fatigue. The score assigned to the questions is summed separately to questions that assess physical fatigue, for those that assess mental fatigue and all questions together to an aggregate score, the total fatigue. Higher values of scores indicate higher fatigue.

\section{Measuring anxiety of hospitalized HF patients}

To evaluate anxiety, the Self-rating Anxiety Scale (SAS) - Zung scale was used [23]. The SAS scale consists of 20 questions that evaluate how respondents felt during the previous week. Respondents have the ability to answer each question on a four-point Likert type scale. In five questions it is first necessary to reverse the scores. The scores attributed to the questions are summed up, leading to a final score ranging from 20 to 80 . Higher scores indicate higher levels of anxiety.

\section{Measuring adherence to therapeutic guidelines of hospitalized HF patients}

To evaluate patients' adherence to therapeutic guidelines a questionnaire in Greek was used [24]. The questionnaire includes 8 questions assessing patients' adherence to therapeutic guidelines. For these 8 questions, respondents are able to answer in a Likert type scale (scores from 1 to 5). Question 1 and question 7 have an inverse score. The score assigned is summed, leading to an aggregate score, the adherence to therapeutic guidelines. Higher values of the score indicate higher adherence. (Questionnaire is available in appendix.)

\section{Statistical analysis}

Categorical data are presented in absolute and relative (\%) frequencies, whereas continuous data are presented as median and interquartile range. The Kruskal-Wallis test was used to test the existence of an association between the quality of life and a factor with more than two categories, while the Mann-Whitney test was used to test for the existence of an association between QoL and a factor with two categories. The association between QoL and anxiety, fatigue and adherence to therapeutic guidelines was assessed with Spearman's rho coefficient. Moreover, multiple linear regression was performed to estimate the effect of patients' characteristics and anxiety, fatigue and adherence to therapeutic guidelines on QoL. Results are presented as regression coefficients (b-coefficients) and 95\% confidence interval (95\% $\mathrm{Cl})$. The level of statistical significance was set to $a=5 \%$. All statistical analyses were performed using the SPSS version 20 package (SPSS Inc, Chicago, IL, USA).

\section{Results}

Table I presents the results related to anxiety, fatigue, adherence to therapeutic guidelines and patients' QoL.

Regarding anxiety, half the patients scored above 47 and $25 \%$ of them scored above 54 . These values indicate moderate levels of anxiety.

Moreover, it is observed that in the total score of fatigue, at least $50 \%$ of participants scored below 70 (median) and below 44 (median) and 28 (median) for physical and mental fatigue, respectively. Regarding the total score it was found that $25 \%$ of the participants had a score higher than 81 . Accordingly, with regard to physical and mental fatigue, $25 \%$ of enrolled patients had a score higher than 48 and 33, respectively. These values indicate moderate to large effects of HF on fatigue.

Regarding adherence to therapeutic guidelines, at least $50 \%$ of patients scored above 28 , indicating high levels of adherence. 
Furthermore, in total score of QoL, at least $50 \%$ of the patients scored above 68 (median) and above 33 (median) and 15 (median) for the physical and mental state, respectively. Regarding total QoL score, it was found that $25 \%$ of the participants had a score higher than 77. Accordingly, with regard to the physical and mental state, $25 \%$ of enrolled patients had a score higher than 36 and 19, respectively. These values indicate moderate to large effects of HF on QoL.

Table II presents the characteristics of the sample. Of 120 participants men constituted $61.7 \%$, $63.3 \%$ of the sample were over 70 years old, $55 \%$ were married, $49.6 \%$ had a primary school education and $68.3 \%$ were pensioners. In terms of clinical status, $41.5 \%$ had NYHA IV, $80.7 \%$ had been hospitalized for the same reason before, $69.5 \%$ had insomnia, $74.6 \%$ experienced paroxysmal nocturnal dyspnea, $80.2 \%$ had a leg edema and $86.4 \%$ had limited their daily activities. According to patients' perceptions, $70.3 \%$ felt very or sufficiently supported by nurses, $83.9 \%$ would like to have early follow-up after hospital discharge, $78 \%$ reported experiencing high or moderate uncertainty about the future and $28.8 \%$ felt not very/ not at all confident to manage symptoms after hospital discharge (Table II).

Patients' characteristics (demographic and self-reported) and their association with MLHF Questionnaire scores

Apart from patients' characteristics, Table II presents the associations between QoL and patients' characteristics (demographic and self-reported).

Total QoL score was statistically significantly associated with NYHA $(p=0.002)$, paroxysmal nocturnal dyspnea, $(p=0.001)$, and leg edema ( $p=$ $0.001)$, whether patients had limited daily activities ( $p=0.001)$, whether they experienced uncertainty about the future $(p=0.001)$, whether they would like to have early follow-up after hospital discharge $(p=0.001)$ and whether they felt confident to manage symptoms after hospital discharge $(p=0.005)$. Specifically, worse total QoL (higher scores) was found for patients with NYHA IV, those with paroxysmal nocturnal dyspnea or leg edema, as well as those who had limited daily activities, who felt uncertainty about the future, who would like to have early follow-up after hospital discharge and finally those who were a little or not confident to manage symptoms after hospital discharge.

The physical state of QoL was statistically significantly associated with sex $(p=0.042)$, NYHA $(p=0.001)$, insomnia $(p=0.007)$, paroxysmal nocturnal dyspnea $(p=0.001)$, leg edema $(p=0.001)$, whether patients had limited daily activities or experienced uncertainty about the future $(p=0.001$
Table I. Measuring anxiety, fatigue, adherence to therapeutic guidelines and QoL in hospitalized HF patients

\begin{tabular}{|c|c|}
\hline Parameter & Median (IQR) \\
\hline Anxiety (Zung) (range: 20-80) & $47(39-54)$ \\
\hline \multicolumn{2}{|l|}{ Fatigue: } \\
\hline Total Score (range: $21-105)$ & $70(61-81)$ \\
\hline Physical (range: 11-55) & $44(37-48)$ \\
\hline Mental (range: 10-50) & $28(21-33)$ \\
\hline $\begin{array}{l}\text { Adherence to therapeutic } \\
\text { guidelines (range: } 8-40 \text { ) }\end{array}$ & $28(25-32)$ \\
\hline \multicolumn{2}{|l|}{ QoL (Minnesota): } \\
\hline Total Score (range: 0-105) & $68(58-77)$ \\
\hline Physical State (range: 0-40) & $33(28-36)$ \\
\hline Mental State (range: 0-25) & $15(10-19)$ \\
\hline
\end{tabular}

$I Q R$ - interquartile range.

and $p=0.001$, respectively), whether they would like to have early follow-up after hospital discharge $(p=0.001)$ and how confident they were to manage symptoms after hospital discharge $(p=0.042)$. Specifically, worse QoL in physical state was found for female participants, with NYHA IV, with insomnia, paroxysmal nocturnal dyspnea and leg edema as well as those who had limited daily activities, experienced high or moderate uncertainty about the future, who would like to have early follow-up after hospital discharge and finally those who were a little or not confident to manage symptoms after hospital discharge.

The mental state of QoL was statistically significantly associated with paroxysmal nocturnal dyspnea $(p=0.015)$, leg edema $(p=0.002)$ as well as whether patients felt supported by nurses $(p=$ 0.029), whether they had limited their daily activities or experienced uncertainty about the future ( $p=0.001$ and $p=0.001$, respectively), whether they would like to have early follow-up after hospital discharge $(p=0.003)$ and finally whether they felt confident to manage symptoms after hospital discharge $(p=0.005)$. Specifically, worse QoL in mental state was found for patients with paroxysmal nocturnal dyspnea and leg edema as well as those who did not feel supported by nurses, who limited daily activities, who experienced uncertainty about the future, who would like to have early follow-up after hospital discharge and finally those who were a little or not confident to manage symptoms after hospital discharge.

Associations between anxiety, fatigue, adherence to guidelines and patients' QoL

Table III presents the associations between anxiety, fatigue, adherence to guidelines and QoL. 
Table II. Patients' characteristics (demographic and self-reported) and their association with MLHF Questionnaire scores

\begin{tabular}{|c|c|c|c|c|c|c|c|}
\hline \multirow[t]{2}{*}{ Parameter } & \multirow[t]{2}{*}{$N(\%)$} & \multicolumn{2}{|c|}{ Total MINNESOTA } & \multicolumn{2}{|c|}{ Physical State } & \multicolumn{2}{|c|}{ Mental State } \\
\hline & & Median (IQR) & $P$-value & Median (IQR) & $P$-value & Median (IQR) & $P$-value \\
\hline Sex: & & & 0.142 & & 0.042 & & 0.252 \\
\hline Male & $74(61.7)$ & $66(53-78)$ & & $31.5(25-35.5)$ & & $14.5(7.5-18.5)$ & \\
\hline Female & $46(38.3)$ & $69(62-76)$ & & $35(31-37)$ & & $17(13-19)$ & \\
\hline Age [years]: & & & 0.546 & & 0.944 & & 0.073 \\
\hline$\leq 70$ & $44(36.7)$ & $61.5(57-72)$ & & $28.5(25-35)$ & & $15(9-17)$ & \\
\hline 70 & $76(63.3)$ & $69(60.5-78)$ & & $34(29.5-37)$ & & $15.5(11-19.5)$ & \\
\hline Marital status: & & & 0.384 & & 0.307 & & 0.204 \\
\hline Married/living together & $69(57.5)$ & $67(56-76)$ & & $32(26-35)$ & & $14(9-17)$ & \\
\hline Single/divorced/widowed & $51(42.5)$ & $69(60-79)$ & & $34(30-37)$ & & $17(12-21)$ & \\
\hline Education: & & & 0.277 & & 0.313 & & 0.173 \\
\hline Primary & $59(49.6)$ & $69(60-76)$ & & $34(29-37)$ & & $16(13-19)$ & \\
\hline Secondary & $31(26.1)$ & $67(50-77)$ & & $33(24-36)$ & & $14(4-17)$ & \\
\hline University & $24(20.2)$ & $63(58-79)$ & & $31(28-35)$ & & $14(6-19)$ & \\
\hline NYHA: & & & 0.002 & & 0.001 & & 0.066 \\
\hline$|-|||$ & $69(58.5)$ & $63(41-70)$ & & $30(18-33)$ & & $12(5-17)$ & \\
\hline IV & $49(41.5)$ & $76(64.5-80.5)$ & & $35.5(32.5-38)$ & & $14.5(11-20)$ & \\
\hline Previous hospitalization: & & & 0.117 & & 0.068 & & 0.144 \\
\hline No & $21(19.3)$ & $64(50-69)$ & & $32(24-36)$ & & $14(9-16)$ & \\
\hline Yes & $88(80.7)$ & $68(58-78)$ & & $33(28-36)$ & & $15.5(10.5-20)$ & \\
\hline $\begin{array}{l}\text { Do you feel supported by } \\
\text { nurses? }\end{array}$ & & & 0.149 & & 0.579 & & 0.029 \\
\hline Very & $40(33.9)$ & $69(56-78)$ & & $34(27-35.5)$ & & $14.5(5-18.5)$ & \\
\hline Enough & $43(36.4)$ & $68(59-77)$ & & $32(27-37)$ & & $14(13-19)$ & \\
\hline A little/not at all & $35(29.7)$ & $67(57-76)$ & & $33(28-36)$ & & $17(10-19)$ & \\
\hline Insomnia: & & & 0.060 & & 0.007 & & 0.122 \\
\hline No & $36(30.5)$ & $59(40.5-68.5)$ & & $27.5(24-32.5)$ & & $13(3-16)$ & \\
\hline Yes & $82(69.5)$ & $70(62-78)$ & & $35(29-37)$ & & $17(13-20)$ & \\
\hline Paroxysmal nocturnal dyspnea: & & & 0.001 & & 0.001 & & 0.015 \\
\hline No & $30(25.4)$ & $53.5(37-66)$ & & $25(16-32)$ & & $11.5(5-15)$ & \\
\hline Yes & $88(74.6)$ & $71(61.5-79)$ & & $35(30-37)$ & & $16.5(13-20)$ & \\
\hline Leg edema: & & & 0.001 & & 0.001 & & 0.002 \\
\hline No & $23(19.8)$ & $56(37-60)$ & & $27(16-31)$ & & $10(5-14)$ & \\
\hline Yes & $93(80.2)$ & $70(62-79)$ & & $35(30-37)$ & & $17(13-20)$ & \\
\hline $\begin{array}{l}\text { Have you limited daily } \\
\text { activities? }\end{array}$ & & & 0.001 & & 0.001 & & 0.001 \\
\hline No & $16(13.6)$ & $42(17-58.5)$ & & $18(8-30)$ & & $7(3-10.5)$ & \\
\hline Yes & $102(86.4)$ & $69(61-78)$ & & $34(28-37)$ & & $16(13-19)$ & \\
\hline
\end{tabular}


Table II. Cont.

\begin{tabular}{|c|c|c|c|c|c|c|c|}
\hline \multirow[t]{2}{*}{ Parameter } & \multirow[t]{2}{*}{$N(\%)$} & \multicolumn{2}{|c|}{ Total MINNESOTA } & \multicolumn{2}{|c|}{ Physical State } & \multicolumn{2}{|c|}{ Mental State } \\
\hline & & Median (IQR) & $P$-value & Median (IQR) & $P$-value & Median (IQR) & $P$-value \\
\hline $\begin{array}{l}\text { Do you experience } \\
\text { uncertainty about the future? }\end{array}$ & & & 0.001 & & 0.001 & & 0.001 \\
\hline Very much & $46(39.0)$ & $73.5(68-82)$ & & $35(33-37)$ & & $17.5(14-21)$ & \\
\hline Moderate & $46(39.0)$ & $68(60-77)$ & & $33.5(28-36)$ & & $16(13-18)$ & \\
\hline A little/not at all & $26(22.0)$ & $50.5(32-58)$ & & $24(14-30)$ & & $5(3-10)$ & \\
\hline $\begin{array}{l}\text { Would you like early follow- } \\
\text { up after hospital discharge? }\end{array}$ & & & 0.001 & & 0.001 & & 0.003 \\
\hline No & $19(16.1)$ & $56(37-60)$ & & $28(16-32)$ & & $10(3-16)$ & \\
\hline Yes & 99 (83.9) & 70 (62-78) & & $34(28-37)$ & & $16(13-20)$ & \\
\hline $\begin{array}{l}\text { How confident do you feel } \\
\text { to manage symptoms after } \\
\text { hospital discharge? }\end{array}$ & & & 0.005 & & 0.042 & & 0.005 \\
\hline Very & $23(19.5)$ & $58(44-68)$ & & $30(25-34)$ & & $9(4-17)$ & \\
\hline Enough & $61(51.7)$ & 67 (58-74) & & $33(27-36)$ & & $14(11-17)$ & \\
\hline A little/not at all & $34(28.85)$ & $74.5(69-82)$ & & $36(32-37)$ & & $18.5(15-21)$ & \\
\hline
\end{tabular}

$I Q R$ - interquartile range.

A statistically significant positive linear association was observed between anxiety and QoL (rho $>0.6$ ) as well as fatigue and QoL (rho >0.3). An increase in the anxiety or fatigue score indicates an increase also in QoL score, meaning that the more anxiety and the more fatigue a patient feels the worse is the QoL. Moreover, a statistically significant negative linear association was observed between adherence to guidelines and QoL (rho $<-0.2)$. An increase in adherence score indicates a decrease in QoL score, meaning that the more adherent a patient is, the better is the QoL.

Impact of anxiety, fatigue, adherence to guidelines on patients' QoL

Multiple linear regression was performed in order to assess the effect of anxiety, fatigue and adherence to guidelines on patients' QoL, adjusting for other possible demographic confounders (those that were univariately found to be significantly associated with quality of life, as stated in the previous section). Table IV presents the results.

As far as total QoL score is concerned, after adjustment of demographic confounders no effect of anxiety, fatigue and adherence to guidelines was observed. It was found that patients who experienced paroxysmal nocturnal dyspnea or had leg edema had an 11.41 and 8.76 points, respectively, higher score in the Minnesota scale than those who did not ( $p=0.001,95 \% \mathrm{Cl}: 5.04-17.78$ and $p=0.018,95 \% \mathrm{Cl}: 1.60-15.92$ respectively). Likewise, patients who had limited daily activities had 18.46 points higher score in the Minnesota

Table III. Associations between anxiety, fatigue, adherence to guidelines and QoL

\begin{tabular}{|c|c|c|c|c|c|c|}
\hline \multirow[t]{2}{*}{ Variable } & \multicolumn{2}{|c|}{ Total MINNESOTA } & \multicolumn{2}{|c|}{ Physical State } & \multicolumn{2}{|c|}{ Mental State } \\
\hline & $\begin{array}{l}\text { Spearman's } \\
\text { rho }\end{array}$ & $P$-value & $\begin{array}{l}\text { Spearman's } \\
\text { rho }\end{array}$ & $P$-value & $\begin{array}{l}\text { Spearman's } \\
\text { rho }\end{array}$ & $P$-value \\
\hline Anxiety & 0.687 & $<0.001$ & 0.772 & $<0.001$ & 0.741 & $<0.001$ \\
\hline \multicolumn{7}{|l|}{ Fatigue: } \\
\hline Total & 0.608 & $<0.001$ & 0.598 & $<0.001$ & 0.495 & $<0.001$ \\
\hline Physical & 0.613 & $<0.001$ & 0.693 & $<0.001$ & 0.390 & $<0.001$ \\
\hline Mental & 0.454 & $<0.001$ & 0.382 & $<0.001$ & 0.471 & $<0.001$ \\
\hline Adherence & -0.251 & 0.012 & -0.250 & 0.013 & -0.340 & 0.001 \\
\hline
\end{tabular}


Table IV. Impact of factors associated with QoL

\begin{tabular}{|c|c|c|c|}
\hline \multirow[t]{2}{*}{ Variable } & \multicolumn{3}{|c|}{ B coef. $(95 \% \mathrm{Cl})$} \\
\hline & Total MINNESOTA & Physical State & Mental State \\
\hline \multicolumn{4}{|l|}{ Crude regression: } \\
\hline Anxiety Zung & $1.33(1.04-1.62)^{\star}$ & $0.65(0.51-0.78)^{*}$ & $0.43(0.32-0.54)^{\star}$ \\
\hline \multicolumn{4}{|l|}{ Fatigue: } \\
\hline Total & $0.67(0.51-0.83)^{\star}$ & $0.33(0.25-0.40)^{*}$ & $0.20(0.13-0.26)^{\star}$ \\
\hline Physical & $1.32(1.04-1.60)^{\star}$ & $0.67(0.55-0.80)^{*}$ & $0.33(0.21-0.45)^{\star}$ \\
\hline Mental & $0.85(0.53-1.17)^{\star}$ & $0.38(0.23-0.54)^{*}$ & $0.30(0.19-0.41)^{\star}$ \\
\hline Adherence to guidelines & $-0.91(-1.51--0.31)^{\star}$ & $-0.43(-0.72--0.14)^{\star}$ & $-0.41(-0.62--0.21)^{*}$ \\
\hline \multicolumn{4}{|l|}{ Adjusted regression: } \\
\hline Anxiety Zung & $0.16(-0.27-0.59)$ & $0.25(0.05-0.46)^{*}$ & $0.20(0.03-0.36)^{\star}$ \\
\hline \multicolumn{4}{|l|}{ Fatigue: } \\
\hline Total & $0.03(-0.38-0.45)$ & $-0.13(-0.32-0.06)$ & $0.10(-0.03-0.23)$ \\
\hline Physical & $0.46(-0.31-1.22)$ & $0.54(0.19-0.88)^{*}$ & $-0.13(-0.37-0.11)$ \\
\hline Mental & $(\text { Omitted })^{\star *}$ & $(\text { Omitted) })^{\star \star}$ & $(\text { Omitted) })^{\star \star}$ \\
\hline Adherence to guidelines & $0.00(-0.48-0.48)$ & $0.08(-0.14-0.30)$ & $-0.07(-0.26-0.13)$ \\
\hline \multicolumn{4}{|l|}{ Sex: } \\
\hline Male & - & Ref. Cat. & - \\
\hline Female & - & $0.48(-2.47-3.42)$ & - \\
\hline \multicolumn{4}{|l|}{ NYHA: } \\
\hline$|-|||$ & Ref. Cat. & Ref. Cat. & - \\
\hline IV & $-2.69(-8.93-3.55)$ & $-0.62(-3.48-2.24)$ & - \\
\hline \multicolumn{4}{|c|}{ Do you feel supported by nurses? } \\
\hline Very & - & - & Ref. Cat. \\
\hline Enough & - & - & $1.62(-0.85-4.10)$ \\
\hline A little/not at all & - & - & $-0.06(-2.71-2.59)$ \\
\hline \multicolumn{4}{|l|}{ Insomnia: } \\
\hline No & - & Ref. Cat. & - \\
\hline Yes & - & $-0.61(-3.72-2.49)$ & - \\
\hline \multicolumn{4}{|c|}{ Paroxysmal nocturnal dyspnea? } \\
\hline No & Ref. Cat. & Ref. Cat. & Ref. Cat. \\
\hline Yes & $11.41(5.04-17.78)^{\star}$ & $6.10(3.24-8.95)^{*}$ & $-0.38(-2.99-2.24)$ \\
\hline \multicolumn{4}{|l|}{ Do you have leg edema? } \\
\hline No & Ref. Cat. & Ref. Cat. & Ref. Cat. \\
\hline Yes & $8.76(1.60-15.92)^{\star}$ & $2.74(-0.54-6.03)$ & $1.34(-1.51-4.20)$ \\
\hline \multicolumn{4}{|c|}{ Have you limited daily activities? } \\
\hline No & Ref. Cat. & Ref. Cat. & Ref. Cat. \\
\hline Yes & $18.46(6.48-30.45)^{*}$ & $7.43(1.84-13.02)^{\star}$ & $1.36(-2.63-5.36)$ \\
\hline
\end{tabular}


Table IV. Cont.

\begin{tabular}{|c|c|c|c|}
\hline \multirow[t]{2}{*}{ Variable } & \multicolumn{3}{|c|}{ B coef. $(95 \% \mathrm{Cl})$} \\
\hline & Total MINNESOTA & Physical State & Mental State \\
\hline \multicolumn{4}{|c|}{$\begin{array}{l}\text { Do you experience uncertainty } \\
\text { about the future? }\end{array}$} \\
\hline Very much & Ref. Cat. & Ref. Cat. & Ref. Cat. \\
\hline Moderate & $-3.21(-9.05-2.62)$ & $-0.27(-2.95-2.40)$ & $0.05(-2.17-2.26)$ \\
\hline A little/not at all & $-13.29(-21.64--4.95)^{*}$ & $-3.37(-7.14-0.41)$ & $-3.94(-7.34--0.54)^{*}$ \\
\hline \multicolumn{4}{|c|}{$\begin{array}{l}\text { Would you like early follow-up } \\
\text { after hospital discharge? }\end{array}$} \\
\hline No & Ref. Cat. & Ref. Cat. & Ref. Cat. \\
\hline Yes & $-10.63(-21.50-0.25)$ & $-2.68(-7.64-2.28)$ & $1.36(-2.10-4.83)$ \\
\hline \multicolumn{4}{|c|}{$\begin{array}{l}\text { How confident do you feel to } \\
\text { manage symptoms after hospital } \\
\text { discharge? }\end{array}$} \\
\hline Very & Ref. Cat. & Ref. Cat. & Ref. Cat. \\
\hline Enough & $-5.94(-12.91-1.02)$ & $-1.52(-4.90-1.85)$ & $-0.04(-2.76-2.67)$ \\
\hline A little/not at all & $-0.85(-9.08-7.38)$ & $-2.57(-6.41-1.26)$ & $1.27(-2.02-4.55)$ \\
\hline
\end{tabular}

*Statistically significant coefficient, ${ }^{* \star}$ omitted due to multicollinearity. Ref. Cat. - Reference category, Cl - Confidence interval.

scale than those who did not $(p=0.003,95 \% \mathrm{Cl}$ : 6.48-30.45). Moreover, patients who did not at all experience uncertainty about the future or a little had a 13.29 points lower score in the Minnesota scale than those who experienced a lot $(p=0.002$, 95\% Cl: $-21.64--4.95)$ ).

Regarding physical state, it was found that an increase of one point in the anxiety score and physical fatigue indicates a worsening of 0.25 and 0.54 points respectively in physical state $(p=0.018,95 \% \mathrm{Cl}: 0.05-0.46$ and $p=0.003$, 95\% Cl: 0.19-0.88 respectively). Moreover, patients who experienced paroxysmal nocturnal dyspnea or had limited daily activities had a 6.10 and 7.43 points, respectively, higher score in physical state than those who did not $(p=0.001,95 \%$ $\mathrm{Cl}: 3.24-8.95$ and $p=0.010,95 \% \mathrm{Cl}: 1.84-13.02$ respectively).

Regarding mental state, it was found that an increase of one point in anxiety score indicates a worsening of 0.20 points in mental state $(p=$ $0.019,95 \% \mathrm{Cl}: 0.03-0.36)$. Moreover, patients who did not at all experience uncertainty about the future or only a little had a 3.94 points lower score in mental state compared to those who experienced it a lot $(p=0.024,95 \% \mathrm{Cl}:-7.34-0.54)$.

\section{Discussion}

The results of the present study showed moderate levels of anxiety, high adherence to therapeutic guidelines as well as moderate to high effects of HF on fatigue and on QoL.
Bibliography research showed three studies exploring QoL in hospitalized HF patients in Greece. Aggelopoulou et al. [25] found poor QoL in 231 Greek hospitalized HF patients (mean age: $66.1 \pm 10.1)$ using the Minnesota questionnaire (MLHFQ score $65.4 \pm 20.6$ ). Using the same instrument (MLHFQ) Audi et al. [11] demonstrated moderate effects of HF on QoL in 300 hospitalized HF patients, of whom $90 \%$ were above 60 years old. An earlier study (2008) conducted by Spiraki et al. [26], showed low QoL and moderate improvements after treatment.

According to the present results, QoL was associated with reports of limitations regarding daily activities, and uncertainty about the future. Indeed, this life-threatening disease imposes several functional or emotional restrictions that result in poor QoL $[11,16]$. Strikingly more HF patients, who perceive themselves as a burden to family, may especially limit their physical and social activities or discontinue their treatment [27]. An encouraging finding of our study is that QoL was associated with patients' desire for early follow-up. Interestingly, follow-up visits are associated with a reduction in readmission risk. Also of importance is the timing of follow-up since visits within 7 days after hospital discharge are helpful in preventing 30-day readmissions [28, 29].

Moreover, lack of confidence to manage symptoms was associated with QoL, thus illustrating the importance of increasing self-management which refers to actively identifying symptoms and 
seeking medical advice [30, 31]. A recent review of $\mathrm{HF}$ management demonstrated the need to promote understanding of the nature and complexities of this progressive disease and its self-care tasks [30].

The current findings demonstrated moderate levels of anxiety. Anxiety is 4 to 5 times more frequent in HF compared to the general population, with prevalence rates between $11 \%$ and $70 \%$ [3234]. Anxiety is associated with adverse outcomes in HF as well as with increased physical impairment (in movement and in conducting ordinary activities) and higher suicidality. Possibly, HF patients view suicide as a solution for their somatic pain and disability [35-37]. Depression as a predictor of worse prognosis in HF emphasizes urgent clinical evaluation since anxiety is often presented concurrently [33, 37]. Anxiety and depression may have equal or even more negative consequences compared to traditional risk factors such as diabetes mellitus, hypertension, smoking, and hypercholesterolemia. Given the high frequency of this comorbidity in HF and its devastating effects, management guidelines recommend their routine assessment. However, these recommendations are not applied in daily clinical practice [32].

Data also revealed that an increase in anxiety indicated worse QoL. AbuRuz [32] showed anxiety as an independent predictor for poor QoL in 200 HF outpatients. A recent study on HF showed that an increase in anxiety score by one unit implied an increase in QoL by 1.22 points (worse QoL) but it is noteworthy that participants were outpatients and not hospitalized [33].

Additionally, the results showed moderate to large effects of HF on fatigue and that an increase in fatigue indicated worse QoL. Fatigue frequency ranges from $69 \%$ to $88 \%$ in HF patients and may vary globally due to diversity in assessment methods [38, 39]. Fatigue is associated with restricted physical ability [38] and along with dyspnea and increased NYHA classification is associated with diminished QoL [40]. Schjoedt et al. [41] reported that the unpredictability and the fluctuation of fatigue are associated with several limitations in daily activities and increased dependency on others. Patients try to maintain balance between adjusting to and struggling against fatigue. Moreover, fatigue was shown as a predictor for disease deterioration among $3029 \mathrm{HF}$ patients in 58 months follow-up [42]. This non-specific, invisible and subjective symptom is characterized as a vicious circle since its consequences further exaggerate this experience [38, 43, 44]. Hopefully, understanding factors associated with fatigue will enhance individualized care and implementation of appropriate strategies $[45,46]$. A recent study on HF outpatients showed that fatigue was asso- ciated with NYHA stage, confidence to acknowledge health deterioration, decrease in appetite, dyspnea at night, edema in lower limbs, relations with health professionals, limitations in daily or social activities and financial worries [47].

Analysis of data showed that an increase in the adherence score indicated better QoL. Silavanich et al. [48] found a positive relationship between medication adherence and QoL among $180 \mathrm{HF}$ patients. Adherence to diet (low sodium and low fat), to medication and to fluid restrictions positively affects QoL, and prevents hospitalizations and death, whereas non-adherence is associated with symptom deterioration [49, 50]. Having as the ultimate goal to improve QoL, it is crucial to enhance adherence in several ways such as psychosocial support, education, counseling, and scheduled telephone contacts, to evaluate self-efficacy behaviors [51]. It is equally important to provide such a clinical environment that fulfills patients' needs and finally ensures a smooth transition to home. Last but not least, adherence as reported by patients may not accurately reflect reality as they have the tendency to conceal their deviations. Therefore, understanding adherence requires a multi-method approach to provide an accurate picture of whether and how medical recommendations are being followed [52].

Several limitations of our study must be acknowledged. First, convenience sampling is one of the limitations as this method is not representative of the whole hospitalized population with $\mathrm{HF}$ living in Greece, thus limiting the generalizability of the results.

The sample size was relatively small, although many significant associations were observed. Furthermore, there was no longitudinal design with follow-up data on the same patients which may permit evaluation of possible changes in all dimensions (anxiety, fatigue, treatment adherence). It would be interesting to monitor anxiety, fatigue, and treatment adherence 12 or 24 months after baseline. Finally, self-report questionnaires are not sufficiently precise to make a psychiatric diagnosis of anxiety. Regarding adherence, patients in their self-report have the tendency to conceal the truth.

The strengths of the study include: $a$ ) the use of a widespread instrument, Minnesota Living With Heart Failure Questionnaire, that may permit comparisons among HF populations across the world and b) the state of "hospitalization" as most research is conducted either in the community or in the outpatient department of the hospital when $\mathrm{HF}$ patients attend their follow-up.

In conclusion, QoL in HF patients is associated with NYHA, paroxysmal nocturnal dyspnea, leg edema, limitations regarding daily activities 
or uncertainty about the future, patients' desire for early follow-up and patients' confidence about symptom management. Moreover, an increase in the anxiety and fatigue score indicates an increase also in QoL (worse QoL) while an increase in the adherence score indicates a decrease in the QoL score (better QoL).

QoL measures may alert health professionals to areas that would otherwise be overlooked in clinical settings where attention is focused on the biological dimension of HF. Before hospital discharge, clinicians may plan therapeutic strategies and early follow-up with the ultimate goal to improve symptoms and QoL.

The present findings encourage a multidisciplinary team to work together to manage this progressive, complex and chronic disease.

\section{Conflict of interest}

The authors declare no conflict of interest.

\section{References}

1. Savarese G, Lund LH. Global public health burden of heart failure. Card Fail Rev 2017; 3: 7-11.

2. Chaudhry SP, Stewart GC. New pharmacological and technological management strategies in heart failure. Vasc Health Risk Manag 2017; 13: 111-21.

3. Cooper LB, DeVore AD, Michael Felker G. The impact of worsening heart failure in the United States. Heart Fail Clin 2015; 11: 603-14.

4. Zaya M, Phan A, Schwarz ER. Predictors of re-hospitalization in patients with chronic heart failure. World J Cardiol 2012; 4: 23-30.

5. Writing Group M. Mozaffarian D, Benjamin EJ, Go AS, et al. Heart disease and stroke statistics - 2016 update: a report from the American Heart Association. Circulation 2016; 133: e38-360.

6. Ponikowski P, Voors AA, Anker SD, et al. ESC Guidelines for the diagnosis and treatment of acute and chronic heart failure: the Task Force for the diagnosis and treatment of acute and chronic heart failure of the European Society of Cardiology (ESC) Developed with the special contribution of the Heart Failure Association (HFA) of the ESC. Eur Heart J 2016; 37: 2129-200.

7. Howie-Esquivel J, Carroll M, Brinker E, et al. A strategy to reduce heart failure readmissions and inpatient costs. Cardiol Res 2015; 6: 201-8.

8. Kilgore M, Patel HK, Kielhorn A, Maya JF, Sharma P. Economic burden of hospitalizations of Medicare beneficiaries with heart failure. Risk Manag Healthc Policy 2017; 10: 63-70.

9. Lazkani M, Ota KS. The role of outpatient intravenous diuretic therapy in a transitional care program for patients with heart failure: a case series. J Clin Med Res 2012; 4: 434-8.

10. Hebert K, Dias A, Franco E, Tamariz L, Steen D, Arcement LM. Open access to an outpatient diuresis program in a systolic heart failure disease management program. Congest Heart Fail 2011; 17: 309-13.

11. Audi G, Korologou A, Koutelekos I, et al. Factors affecting health related qol in hospitalized patients with heart failure. Cardiol Res Pract 2017; 2017: 4690458.
12. Gheorghiade M, Vaduganathan M, Fonarow GC, Bonow RO. Re hospitalization for heart failure: problems and perspectives. J Am Coll Cardiol 2013; 61: 391-403.

13. McHugh MD, Ma C. Hospital nursing and 30-day readmissions among Medicare patients with heart failure, acute myocardial infarction, and pneumonia. Med Care 2013; 51: 52-9.

14. Roger VL. Epidemiology of heart failure. Circ Res 2013; 113: 646-59.

15. Sahle BW, Owen AJ, Mutowo MP, Krum H, Reid CM. Prevalence of heart failure in Australia: a systematic review. BMC Cardiovasc Disord 2016; 16: 32.

16. Nieminen MS, Dickstein K, Fonseca C, et al. The patient perspective: QoL in advanced heart failure with frequent hospitalizations. Int J Cardiol 2015; 191: 256-64.

17. Polikandrioti M, Goudevenos J, Michalis LK, et al. Factors associated with depression and anxiety of hospitalized patients with heart failure. Hellenic J Cardiol 2015; 56: 26-35.

18. Lewis EF, Johnson PA, Johnson W, Collins C, Griffin L, Stevenson $L W$. Preferences for $Q \mathrm{~L} L$ or survival expressed by patients with heart failure. J Heart Lung Transplant 2001; 20: 1016-24.

19. Heo S, Lennie TA, Okoli C, Moser DK. QoL in patients with heart failure: ask the patients. Heart Lung 2009; 38: 100-8.

20. Polikandrioti M, Goudevenos J, Michalis LK, et al. Association between characteristics of hospitalized heart failure patients with their needs. Global J Health Sci 2015; 8: 95-108.

21. Rector TS, Kubo SH, Cohn JN. Patients' self-assessment of their congestive heart failure. Part 2: content, reliability and validity of a new measure, the Minnesota Living with Heart Failure Questionnaire. Heart Fail 1987; 3: 198-209.

22. Bakalidou D, Voumvourakis K, Tsourti Z, Papageorgiou E, Poulios A, Giannopoulos S. Validity and reliability of the Greek version of the Modified Fatigue Impact Scale in multiple sclerosis patients. Int J Rehabil Res 2014; 37: 271-6.

23. Samakouri M, Bouhos G, Kadoglou M, Giantzelidou A, Tsolaki K, Llvaditis M Standardization of the Greek version of Zung's Self-Ratting Anxiety Scale. Psychiatriki 2012; 23: 212-20.

24. Manolis K. Adherence to chronic disease. University of Patra, Greece, 2012. Website https://nemertes.lis.upatras.gr/jspui/bitstream/10889/6058/1/Nemertes_Manolis\%28f\%29.pdf (in Greek, post graduate thesis).

25. Aggelopoulou Z, Fotos NV, Chatziefstratiou AA, Giakoumidakis K, Elefsiniotis I, Brokalaki H. The level of anxiety, depression and QoL among patients with heart failure in Greece. Appl Nurs Res 2017; 34: 52-6.

26. Spiraki Ch, Kaitelidou D, Papakonstantinou V, Prezerakos P, Maniadakis N. Health-related quality of life measurement in patients admitted with coronary heart disease and heart failure to a cardiology department of a secondary urban hospital in Greece. Hellenic J Cardiol 2008; 49: 241-7.

27. Johnson JO, Sulmasy DP, Nolan MT. Patients' experiences of being a burden on family in terminal illness. J Hosp Palliat Nurs 2007; 9: 264-9.

28. Tong L, Arnold T, Yang J, Tian X, Erdmann C, Esposito T. The association between outpatient follow-up visits and all-cause non-elective 30-day readmissions: a retrospective observational cohort study. PLoS One 2018; 13: e0200691.

29. Ryan J, Kang S, Dolacky S, Ingrassia J, Ganeshan R. Change in readmissions and follow-up visits as part of 
a heart failure readmission quality improvement initiative. Am J Med 2013; 126: 989-94.

30. Clark AM, Wiens KS, Banner D, et al. A systematic review of the main mechanisms of heart failure disease management interventions. Heart 2016; 102: 707-11.

31. Smeulders ES, Van Haastreqt JC, Janssen-Boyne JJ, et al. Feasibility of a group-based self-management program among congestive heart failure patients. Heart Lung 2009; 38: 499-512.

32. AbuRuz ME. Anxiety and depression predicted QoL among patients with heart failure. J Multidiscip Healthc 2018; 11: 367-73.

33. Polikandrioti M, Panoutsopoulos G, Tsami A, et al. Assessment of quality of life and anxiety in heart failure outpatients. Arch Med Sci Atheroscler Dis 2019; 4: e38-46.

34. Chen CY, Wang CL. Psychiatric comorbidity and psychosocial factors matter in heart failure. Acta Cardiol Sin 2016; 32: 62-4.

35. Tsuchihashi-Makaya M, Kato N, Chishaki A, Takeshita A, Tsutsui $\mathrm{H}$. Anxiety and poor social support are independently associated with adverse outcomes in patients with mild heart failure. Circ J 2009; 73: 280-7.

36. Jiang W, Kuchibhatla M, Cuffe MS, et al. Prognostic value of anxiety and depression in patients with chronic heart failure. Circulation 2004; 110: 3452-6.

37. Serafini G, Pompili $M$, Innamorati $M$, et al. The impact of anxiety, depression, and suicidality on QoL and functional status of patients with congestive heart failure and hypertension: an observational cross-sectional study. Prim Care Companion J Clin Psychiatry 2010; 12: PCC.09m00916.

38. Fini A, de Almeida Lopes Monteiro da Cruz D. Characteristics of fatigue in heart failure patients: a literature review. Rev Lat Am Enfermagem 2009; 17: 557-65.

39. Stephen SA. Fatigue in older adults with stable heart failure. Heart Lung 2008; 37: 122-31.

40. Rector TS, Anand IS, Cohn JN. Relationships between clinical assessments and patients perceptions of the effects of heart failure on their quality of life. J Card Fail 2006; 12: 87-92.

41. Schjoedt I, Sommer I, Bjerrum MB. Experiences and management of fatigue in every day life among adult patients living with heart failure: a systematic review of qualitative evidence. JBI Database System Rev Implement Rep 2016; 14: 68-115.

42. Ekman I, Cleland JG, Swedberg K, et al. Symptoms in patients with heart failure are prognostic predictors. J Card Fail 2005; 11: 288-92.

43. Kessing D, Denollet J, Widdershoven J, Kupper N. Fatigue and self-care in patients with chronic heart failure. Eur J Cardiovasc Nurs 2016; 15: 337-44.

44. Bidwell JT, Higgins MK, Reilly CM, Clark PC, Dunbar SB. Shared heart failure knowledge and self-care outcomes in patient-caregiver dyads. Heart Lung 2017; 47: 32-9.

45. Polikandrioti M, Tzirogiannis K, Zyga S, et al. Assessment of fatigue in patients with a permanent cardiac pacemaker: prevalence and associated factors. Arch Med Sci Atheroscler Dis 2018; 3: e166-73.

46. Polikandrioti M, Kalafatakis F, Koutelekos I, Kokoularis D. Fatigue in heart failure outpatients: levels, associated factors, and the impact on quality of life. Arch Med Sci Atheroscler Dis 2019; 4: e103-12.

47. Polikandrioti M, Tzirogiannis K, Zyga S, et al. Effect of anxiety and depression on the fatigue of patients with a permanent pacemaker. Arch Med Sci Atheroscler Dis 2018; 3: e8-17.
48. Silavanich V, Nathisuwan S, Phrommintikul A, Permsuwan U. Relationship of medication adherence and quality of life among heart failure patients. Heart Lung 2019; 48: 105-10.

49. Corrao G, Rea F, Ghirardi A, Soranna D, Merlino L, Mancia G. Adherence with antihypertensive drug therapy and the risk of heart failure in clinical practice. Hypertension 2015; 66: 742-9.

50. Toback M, Clark N. Strategies to improve self management in heart failure patient. Contemp Nurse 2017; 53: 105-20.

51. Unverzagt S, Meyer G, Mittmann S, Samos FA, Unverzagt $M$, Prondzinsky R. Improving treatment adherence in heart failure. Dtsch Arztebl Int 2016; 113: 423-30.

52. Martin LR, Williams SL, Haskard KB, Dimatteo MR. The challenge of patient adherence. Ther Clin Risk Manag 2005; 1: 189-99. 


\section{Appendix}

Questionnaire for adherence to therapeutic guidelines in heart failure patients

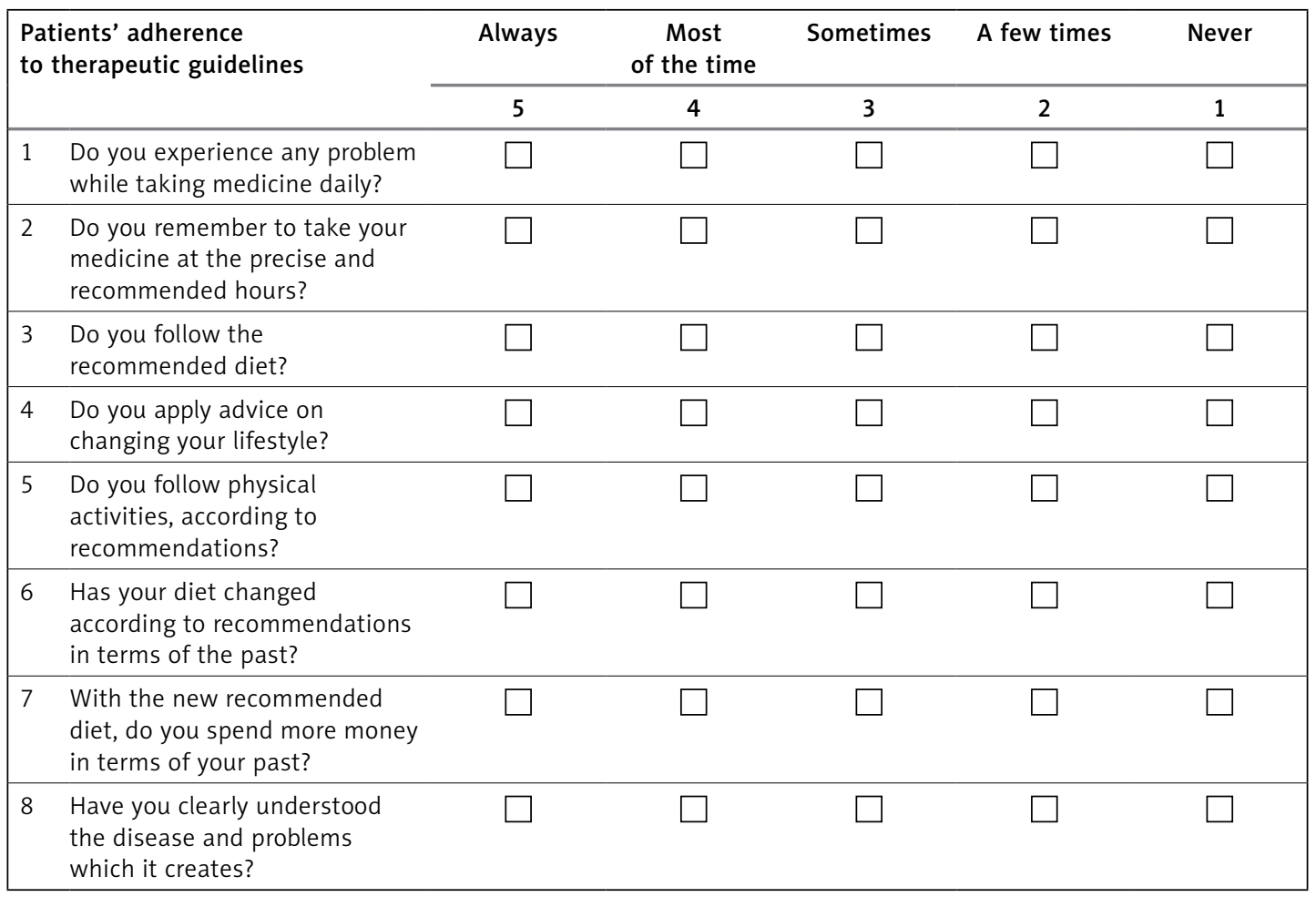

